\title{
ESTIMATING BUILT-UP AREA CHANGE IN ULAANBAATAR CITY, MONGOLIA
}

\author{
Purevtseren Myagmartseren ${ }^{1}$, Indra Myagmarjav ${ }^{2}$, Nergui Enkhtuya ${ }^{1}$, Gantumur Byambakhuu ${ }^{1 *}$, Tsegmed Bazarkhand ${ }^{1}$ \\ ${ }^{1}$ NUM, Department of Geography, NUM \#2, Ulaanbaatar 14200, Mongolia - (myagmartseren, n.enkhtuya, byambakhuu, \\ bazarkhand_ts)@num.edu.mn \\ ${ }^{2}$ Department of Land Management, Mongolian University of Life Sciences, Ulaanbaatar 17024, Mongolia - \\ myagmarjav@muls.edu.mn
}

Commission IV, TCIV/3

KEY WORDS: Urban expansion, Markov chain model, Urban transition matrix, Cellular automata

\begin{abstract}
:
Long-term urban built-up area changes of the Ulaanbaatar city has accelerated since the 1950s and due to rapid urbanization most of the Mongolian population, or about $68 \%$, live in urban areas. The systematic understanding of urban land expansion is a crucial clue for urban land use planning and sustainable land development. Therefore, in this paper, we used a Markov chain model and cellular automata (CA) to simulate and predict current and future built-up areas expansion is Ulaanbaatar. Landsat imageries (Landsat TM 5, Landsat ETM 7 and Landsat OLI 8) of 1988, 1998, 2008, and 2017 were used to derive main land use classes. Clark Lab's (Clark University) Geospatial Monitoring and Model software had been used for the urban expansion prediction. The results are innovated to comparable to validate with other study results by using a different kind of methods. Built-up area expansion modeled and predicted 2028's trends based on a historical expansion of the Ulaanbaatar city between 1988 and 2017, which are prepared according to input model requirements. The built-up area was 7282 hectares (ha) in 1988 and has expanded to 31144 ha in 2017 . The built-up area growth of the Ulaanbaatar city has reached 4.3 times over the past 30 years, and from 2017 to 2028 the expansion of the built-up area will be 1.5 times. A comparison of urban expansion from 1988 to 2017 has revealed a rapid built-up invasion to the previous areas of agriculture, grassland, and forest. Simulation performance of Markov chain with the cellular automata model can be used for an improvement in the understanding of the urban expansion processes while allowing helpful for better planning of Ulaanbaatar city, as well as for other rapidly developing towns of Mongolia.
\end{abstract}

\section{INTRODUCTION}

The main task of governments and communities struggle in our day is how to manage expansion for areas for developing areas in a sustainable way without degrading land values (Myagmartseren et al., 2017; Purevtseren et al., 2018). Urban area spatial dynamics are the most direct and indirect result of the driving force of economic and social changes in a country or region (Sajous et al., 2016). Although urban areas cover less than $4 \%$ of the earth's total land surface (Barrow, 1995), more than half of the world's population resides in urban regions. Urban growth generally leads to an increase in motorized transport, air, water and noise pollution, energy consumption, a loss of agricultural land, and a reduction in biological diversity (Seto and Kaufmann, 2003). Information on existing expansion and the course of spatial change is essential for urban planning and management and provides crucial clues for the future development of Ulaanbaatar urban areas (Myagmartseren et al., 2017; Zhang et al., 2002).

Due to accelerated urbanization since the 1950s, most of the Mongolian population, or about $68 \%$, live in urban areas (Purevtseren et al., 2018). Despite the decision maker's effort to limit centralization, halt an increase in the urban population, and promote out-migration from Ulaanbaatar, the city was constructed to be significantly more population-dense than other Mongolian towns and regional cities. (Sajous et al., 2016). Concerning land use, the city has undergone a dramatic urbanization trend in the last five decades. In the "ger district" (circular nomad's tent-yurts detached to a land lot is a type of slum settlement district in Mongolia) sprawl area, which covers about $32 \%$ of all territory of the city, urban expansion has accelerated so far so it adversely impacts green belt areas, wetlands, riparian zones, open space, and public land (Myagmartseren et al., 2017). In this case, Gantumur et al. (2020) assessed the spatiotemporal dynamics of urban expansion and simulated urban area in 2030 and 2040, were sampled in Ulaanbaatar, Mongolia. Also, another study result is demonstrated to detect the changes in land use/land cover including urban areas, which is extended in the past (Gantumur et al., 2017).

The purpose of this study is to show that a simulation performance of Markov chains with a cellular automata (CA) model can be used for improving the understanding of urban expansion processes while also allowing for better planning of the urban development of Ulaanbaatar city the urban expansion other rapid developing towns of Mongolia. The main findings stated in this paper is that Ulaanbaatar is growing at a high rate and sporadically (Sajous et al., 2016), even though the geometrical growth hasn't been strictly planned and frequently created sprawl.

Most urban studies of Mongolia have been carried out without cellular automata models, instead of focusing on GIS techniques while omitting a data quality of the model. Mongolian urban studies need new conceptual remote sensing tools, some of which are presented in this paper.

\section{STUDY MATERIALS AND METHODS}

Taking Ulaanbaatar as an example, the general scope of this paper is to express opportunities for combining the Markov chain model and CA with geographical information systems (GIS) for the urban expansion simulation and future growth prediction. This will be achieved through fulfilling the following objectives: (i) Landsat image classification of

\footnotetext{
* Corresponding author
} 
Ulaanbaatar land use and land cover of 1988, 1998, 2008, 2017 and identification of land use and land cover changes of that period; (ii) Prediction of the size of urban expansion area using the Markov chain matrix with cellular automata (iii) Perform an accuracy assessment to compare relative certainty of a model with ground truth data using an error matrix.

Landsat imageries (TM, ETM+, and OLI) of 1988, 1998, 2008, and 2017 were used to derive main land use classes. To classify the image, the supervised classification method was used. At the end of the classification, we identified six land-use / land cover classes: forest, grassland, water bodies, agriculture, barren land, and built-up areas. The rate of change of land use from initial years to next time steps was used for the transition state matrix. Land-use change for each land use/cover class $i$ was calculated as Zhang et al. (Aldwaik and Pontius, 2012; Jiyuan et al., 2002; Zhang et al., 2017):

$$
R C_{i}=\left(\left(A+\frac{i}{A_{i}}\right)^{1 / T_{2}-T_{1}}-1\right) \times 100
$$

where $R C_{i}$ is the annual rate of change; $A_{i+}$ and $A_{+i}$ are the areas (in ha) of a land use/cover class $i$ at years; $T_{1}$ is initial time and $T_{2}$ is next time.

A grid of cells derived from remote sensing imageries is a CA modelling basis (C. and K., 2015; Musa et al., 2017). Musa et al. stated that each cell of remote sensing image represents a certain class of land use and its future state is performed in CA according to the neighbourhood cells of it and its former state together in compliance with a function of transition rules (Musa et al., 2017). The general equation is:

$$
S^{t+1}=f\left(S^{t}, N\right)
$$

where $S^{t}$ is the state of cells in the initial time $t ; S^{t+1}$ is the state of cells in the next time $t+1 ; N$ is the state of cells in the neighbourhood and $f$ represents the function of transition rules (Musa et al., 2017).

The perspective of the model and how Markov is focused on numbers, not a geographical location, integrating with a Markov chain model has made CA a more influential urban studies tool since it demonstrates a rate of change among the land use cells that have converted into different classes. The general calculation of Markov chain model for urban spatial change is mathematically written as (Musa et al., 2017):

$$
\begin{gathered}
S(t+1)=P_{i j} * S(t) \\
S_{i j}=\left(\begin{array}{cccc}
P_{11} & P_{12} & \cdots & P_{1 n} \\
P_{21} & P_{22} & \cdots & P_{2 n} \\
\vdots & \vdots & \ddots & \vdots \\
P_{n 1} & P_{n 2} & \cdots & P_{n n}
\end{array}\right) \\
\left(0 \leq P_{i j}<1 \text { and } \sum_{j+1}^{n} P_{i j}=1,(i, j=1,2, \ldots, n)\right)
\end{gathered}
$$

where $S_{t}$ is the state of land use in initial time ${ }^{t} ; S_{t+1}$ is the state of land use in next time $t+1 ; P_{i j}$ is transition probability matrix in a state.
Clark Lab's (Clark University) "Geospatial Monitoring and Model" software was used for 2028's urban expansion prediction (Eastman, 2009).

To improve the study, we used a confusion matrix, since it can provide a variety of measures for mapping analysis accuracy (Tempfli et al., 2001). The most accepted among all measures is the percentage of correctly matched classes, the percentage of misclassified (omitted), and the overall accuracy (Foody, 2002; Lunetta and Lyon, 2019; Tempfli et al., 2001). Another broadly used measure of map accuracy that may be derived from a confusion matrix is the Cohen's kappa coefficient of agreement or the K statistics (Eq.6), which gives a guide to the chance of an agreement between map classification and the reference data (Smits et al., 1999; Stehman and Czaplewski, 1998; Tempfli et al., 2001).

$$
K=\frac{n \sum_{i=1}^{q} n_{i i}-\sum_{i=1}^{q} n_{i+} n_{+i}}{n^{2}-\sum_{i=1}^{q} n_{i+} n_{+i}}
$$

Where $K$ is the kappa coefficient, ${ }^{n_{i}}$ is the number of pixels, $n_{i i}$ is the number of matched pixels, ${ }^{q}$ is the number of classes.

Pontius $\mathrm{Jr}$ and $\mathrm{Si}$ (2014) presents the total operating characteristic (TOC) is most common cross-case comparison method, which shows the total information in the contingency table for each threshold. TOC maintains desirable properties of the relative operating characteristic (ROC), while TOC reveals strictly more information than ROC in a manner that makes TOC more useful than ROC.

\section{ESTIMATING THE CHANGE RESULTS OF BUILT- UP AREA}

Landsat imageries (TM, ETM+, and OLI) of 1988, 1998, 2008, and 2017 were used to derive main land use classes. To classify the image, the supervised classification method was used After land use classification of satellite images, in 1988 there was $44.51 \%$ of agricultural land, $1.85 \%$ of built-up area, $1.17 \%$ of barren land, $31.62 \%$ of the forest, $24.1 \%$ of grassland, $0.4 \%$ of water bodies. By 2017, agricultural land area was $40.8 \%$, builtup area $7.89 \%$, barren land $2.52 \%$, grassland $25.32 \%$, forest $19.51 \%$, water bodies $0.25 \%$, respectively. Comparing these four dates $(1988,1998,2008$, and 2017) shows the 30-year range of land-use changes

\begin{tabular}{|l|l|l|l|}
\hline $\begin{array}{l}\text { Land use/ land } \\
\text { cover class }\end{array}$ & $1988 / 1998$ & $1998 / 2008$ & $2008 / 2017$ \\
\hline Agriculture & -1120 & -1709 & -4945 \\
\hline Built-up & 1413 & 4372 & 18077 \\
\hline Barren land & 207 & 1818 & 3320 \\
\hline Grassland & -28972 & -9841 & -5727 \\
\hline Forest & -6311 & -14040 & -10525 \\
\hline Water & -159 & -282 & -200 \\
\hline
\end{tabular}

Table 1. Land use/cover changes in 30 years

The type of anthropogenic land degradation in the study area is mostly the impact of urbanization processes. Due to the adverse environmental impact of the city's expansion, from 1988 to 2017 the area of barren land and built-up area expansion is increased by 23826 ha. Clark Lab's software calculated the rate of land-use change after we inputted the transition state matrix and cellular automata (Table 1).3 


\begin{tabular}{|c|c|c|c|c|c|c|}
\hline \multirow{2}{*}{$\begin{array}{c}\text { Land use/ } \\
\text { land cover } \\
\text { class }\end{array}$} & \multicolumn{2}{|c|}{$1988 / 1998$} & \multicolumn{2}{|c|}{$1998 / 2008$} & \multicolumn{2}{|c|}{$2008 / 2017$} \\
\hline & $\begin{array}{c}\text { Area } \\
\text { (ha) }\end{array}$ & $\%$ & $\begin{array}{c}\text { Area } \\
\text { (ha) }\end{array}$ & $\%$ & $\begin{array}{c}\text { Area } \\
\text { (ha) }\end{array}$ & $\%$ \\
\hline $\begin{array}{c}\text { Agriculture } \\
\text { to Built-up } \\
\text { area }\end{array}$ & 523 & 27.0 & 1520 & 34.1 & 3677 & 19.7 \\
\hline $\begin{array}{l}\text { Barren to } \\
\text { Built-up }\end{array}$ & - & - & 85 & 1.9 & 550 & 2.9 \\
\hline $\begin{array}{c}\text { Forest to } \\
\text { Built-up } \\
\text { area }\end{array}$ & - & - & 2841 & 63.7 & 8973 & 48.1 \\
\hline $\begin{array}{c}\text { Grassland } \\
\text { Built-up } \\
\text { area }\end{array}$ & 1340 & 69.2 & - & - & 5280 & 28.3 \\
\hline $\begin{array}{c}\text { Water to } \\
\text { Built-up } \\
\text { area }\end{array}$ & 73 & 3.77 & 11 & 0.25 & 147 & 0.7 \\
\hline $\begin{array}{c}\text { Total } \\
\text { transition } \\
\text { of classes } \\
\text { to Built-up } \\
\text { area } \\
\end{array}$ & 1936 & 100 & 4457 & 100 & 18627 & 100 \\
\hline
\end{tabular}

Table 2. Land use/cover classes transition state to built-up class

According to the land use/land cover transition matrix, the area of built-up land was increased by 1936 hectares between 1988 and 1998 and then increased by 4457 ha between 1998 and 2008, a trend of rapidly increasing urban development year after year. In 10 years (from 2008 to 2017) there has been an increase of 18627 ha area of built-up land (Table 2).

\begin{tabular}{|l|l|l|}
\hline Built-up area & Area (ha) & $\%$ \\
\hline 1988 & 7282 & 1.8 \\
\hline 1998 & 8695 & 2.2 \\
\hline 2008 & 13067 & 3.3 \\
\hline 2017 & 31144 & 7.9 \\
\hline 2028 & 47236 & 11.97 \\
\hline
\end{tabular}

Table 3. Built-up area changes detection and prediction

There was a 7282 ha area has been built in 1988 and 31144 ha by 2017 (Table 3), revealing that the urban land use of Ulaanbaatar in the past 30 years increased by 23862 hectares. The built-up land of Ulaanbaatar city area was 31144 ha, of $16.22 \%$ of which are multistory buildings, mostly apartments, and the large majority, $83.78 \%$, was a ger area. In 2017, 576,900 inhabitants, or $41.64 \%$ of the population of Ulaanbaatar city, lived in mid- and high-rise apartment areas, and 860,000 inhabitants, or $58.36 \%$, lived in ger areas. The average density of the population in 2017 was 183 people/ha in mid- and highrise apartment areas and 26 people/ha in ger areas. Using the cellular automata and our Markov chain model, a 2028 simulation predicted the built-up land cover will expand to 47236 hectares (Figure 1) based on the historical urban growth, especially the 4.3 times increase in built-up areas during the past thirty years.

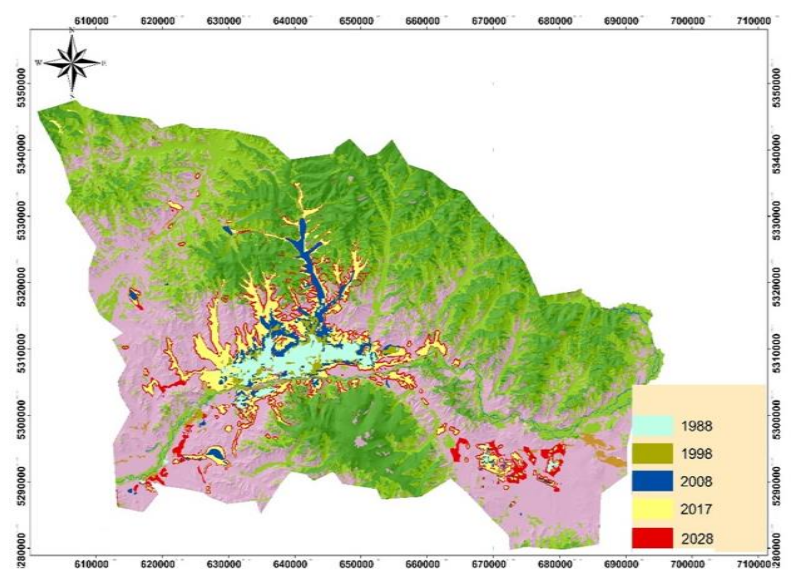

Figure 1. Land-use change (2008- 2017) and model prediction (2028)

For the data validations, and accuracy assessment error matrix was calculated to compare with archived field reference data mapped in two years 1988 and 2009. In general, the classification map we create was sufficiently accurate and closely representative of the referenced field survey data of archived material. The overall accuracy compared with references is 0.93 , meaning that $93 \%$ of the cells are identically classified in both maps. We found that the land use/land cover map resembles previous field survey data assessments of areas with the same classes of land use. Our Markov chain model map corresponded with the field reference map. The Kappa coefficient of land use and land cover map in 2017 had a positive 0.82 value, which indicates that the classified map has a strong agreement with ground truth data. This result showed that the CA-Markov chain model has good potential to accurately predict future land-use changes.

To define the ROC, Figure 2 plots the rate of true positives on the vertical axis versus the rate of false-positives on the horizontal axis for the simulated urban area image of 2028 with an initial urban area. The initial urban area had a rate of ROC with a simulated urban area in 2028, which was 0.52 , respectively (Table 4$)$.

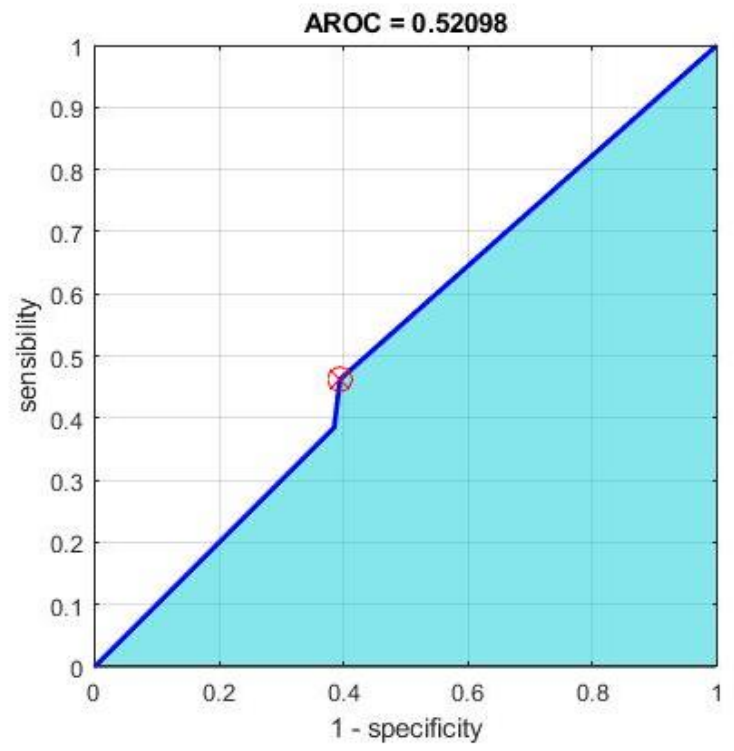

Figure 2. ROC curves to validate models of an initial urban area with simulated urban areas. 


\begin{tabular}{|l|l|l|}
\hline & \multicolumn{2}{|c|}{ ROC Curve Parameters } \\
\hline 1 & Distance & 0.66 \\
\hline 2 & Threshold & 1.00 \\
\hline 3 & Sensitivity & 0.46 \\
\hline 4 & Specificity & 0.61 \\
\hline 5 & AROC & 0.52 \\
\hline 6 & ACC & 0.53 \\
\hline 7 & PPV & 0.54 \\
\hline 8 & NPV & 0.53 \\
\hline 9 & FNR & 0.54 \\
\hline 10 & FPR & 0.39 \\
\hline 11 & FDR & 0.46 \\
\hline 12 & FOR & 0.47 \\
\hline 13 & F1 Score & 0.50 \\
\hline 14 & MCC & 0.07 \\
\hline 15 & BM & 0.07 \\
\hline 16 & MK & 0.07 \\
\hline
\end{tabular}

Table 4. Quantitative parameters of ROC

where PPV and NPV are positive and negative predicted values, FNR and FPR are false negative and positive rates, FDR is false discovery rate, FOR is false omission rate, MCC is Matthews correlation coefficient, BM is In formedness and MK is markedness.

\section{DISCUSSION AND CONCLUSION}

As to our knowledge, no scientific studies have reported on urban geography or sprawl expansion prediction in Mongolia using a Markov chain model and CA. Therefore, in this paper, we used a Markov chain model and CA to simulate and predict past, current, and future built-up areas in Ulaanbaatar city. Mongolians are starting to use GIS with remotely sensed data and CA techniques for urban expansion studies, and the new tool of CA-Markov chain modelling has a successful future in this direction. These tools allow performing environmental and urban planning activities to more precise, quick, and inexpensive. CA and Markov chain model integration is the best suited scientific tool for handling many urban study issues (Ahmed and Ahmed, 2012; Poelmans and Van Rompaey, 2010). CA-Markov chain modelling also is easier for decisionmakers thanks to its tables and maps. Additionally, it demonstrates the effectiveness of using remotely sensed data for sprawl determination.

The built-up area was 7282 ha in 1988 and has expanded to 31144 ha in 2017. The built-up area growth of the Ulaanbaatar city has expanded 4.3 times over the past 30 years. Between 2017 and 2028, the expansion of the built-up area will be 1.5 times greater than the 2017 built-up area size as predicted by our CA-Markov model. From 1988 through 2017, the natural environment notably was altered to either built-up environments or barren land. A comparison of urban expansion from 1988 to 2017 has revealed construction sites and "ger" slum districts rapidly replacing former farmland, grassland, and forest. These types of land-use changes are proving the significant benefit of the CA-Markov model for urban land-use studies, one that Zhang et al. (2017) noted in their study, writing: "common methods of land use/cover change study would miss these dynamics".

Overall, it could be concluded that land use simulation map is generated somewhat correctly according to the result of overall accuracy 0.93 , matched cells $92-95 \%$, and Kappa coefficient 0.82 results. Respectively, the cells modelled for the new expansion area of the Ulaanbaatar had been matched to the current location of ger areas in the urban fringes. Musa et al. (2017) concluded that the CA-Markov model has higher overall accuracy and Kappa coefficient of agreement than the logistic regression model. However, according to Ahmed and Ahmed's study (Ahmed and Ahmed, 2012), the multi-layer perception Markov, a variety we did not use, has the best result for predicting the city's future urban growth (Musa et al., 2017). This means the CA-Markov model highly reliant on the quality of the reference data and the underlying model's calculations, both of which we trust.

\section{ACKNOWLEDGMENT}

We are very thankful to all people for the help, we have had. Especially thanks to B.Bayanjargal and B.Altanbaatar for the collected and processed spatial data preparation. Sincere gratitude to MULS intern Mr. Pearse Anderson for the text edition and language check. This work has been done within the framework of the project P2019-3743 supported by the Asia Research Center, Mongolia and Korea Foundation for Advanced Studies.

\section{REFERENCES}

Ahmed, B., Ahmed, R., 2012. Modeling Urban Land Cover Growth Dynamics Using Multi-Temporal Satellite Images: A Case Study of Dhaka, Bangladesh. 1,3-31.

Aldwaik, S.Z., Pontius, R.G., 2012. Intensity analysis to unify measurements of size and stationarity of land changes by interval, category, and transition. Landscape and Urban Planning 106, 103-114.

Barrow, C.J., 1995. Changes in land use and land cover: A global perspective, edited by W. B. Mayer and B. L. Turner II. Cabridge university press, Cambridge, 1994. ISBN 052147085 4, £35 (hardback), xi +573 pp. 6, 201-202.

Eastman, J.R., 2009. IDRISI TaigaGuide to GIS and Image Processing. Clark University, Clark Labs

Foody, G.M., 2002. Status of land cover classification accuracy assessment. Remote Sensing of Environment 80, 185-201.

Gantumur, B., Wu, F., Vandansambuu, B., Tsegmid, B., Dalaibaatar, E., Zhao, Y., 2020. Spatiotemporal dynamics of urban expansion and its simulation using CA-ANN model in Ulaanbaatar, Mongolia. Geocarto International, 1-16.

Gantumur, B., Wu, F., Zhao, Y., Vandansambuu, B., Dalaibaatar, E., Itiritiphan, F., Shaimurat, D., 2017. Implication of relationship between natural impacts and land use/land cover (LULC) changes of urban area in Mongolia. SPIE.

Jiyuan, L., Mingliang, L., Xiangzheng, D., Dafang, Z., Zengxiang, Z., Di, L., 2002. The land use and land cover change database and its relative studies in China. Journal of Geographical Sciences 12, 275-282.

Lunetta, R.S., Lyon, J.G., 2019. Remote Sensing and GIS Accuracy Assessment. CRC Press, Boca Raton, Florida.

Musa, S.I., Hashim, M., Reba, M.N.M., 2017. A review of geospatial-based urban growth models and modelling initiatives. Geocarto International 32, 813-833.

Myagmartseren, P., Buyandelger, M., Brandt, S.A., 2017. Implications of a Spatial Multicriteria Decision Analysis for Urban Development in Ulaanbaatar, Mongolia. - 2017. 
Poelmans, L., Van Rompaey, A., 2010. Complexity and performance of urban expansion models. Computers, Environment and Urban Systems 34, 17-27.

Pontius Jr, R.G., Si, K., 2014. The total operating characteristic to measure diagnostic ability for multiple thresholds. International Journal of Geographical Information Science 28, 570-583.

Purevtseren, M., Tsegmid, B., Indra, M., Sugar, M., 2018. The Fractal Geometry of Urban Land Use: The Case of Ulaanbaatar City, Mongolia. 7, 67.

Sajous, P., Myagmartseren, P., Munkhnaran, S., 2016. Fresh Perspectives on Urban Dynamics: The Case of Ulaanbaatar (Mongolia) and Le Havre (France).

Seto, K.C., Kaufmann, R.K., 2003. Modeling the Drivers of Urban Land Use Change in the Pearl River Delta, China: Integrating Remote Sensing with Socioeconomic Data. Land Economics 79, 106-121.

Smits, P.C., Dellepiane, S.G., Schowengerdt, R.A., 1999. Quality assessment of image classification algorithms for landcover mapping: A review and a proposal for a cost-based approach. International Journal of Remote Sensing 20, 14611486.

Stehman, S.V., Czaplewski, R.L., 1998. Design and Analysis for Thematic Map Accuracy Assessment: Fundamental Principles. Remote Sensing of Environment 64, 331-344.

Tempfli, K., Kerle, N., Huurneman, G.C., Janssen, L.L.F., 2001. Principles of Remote Sensing: An introductory textbook. The International Institute for Geo-Information Science and Earth Observation (ITC), Enschede, The Netherlands.

Wray, C., Cheruiyot, K., 2015. Key Challenges and Potential Urban Modelling Opportunities in South Africa, with Specific Reference to the Gauteng City-Region. South African Journal of Geomatics 4 .

Zhang, B., Zhang, Q., Feng, C., Feng, Q., Zhang, S., 2017. Understanding Land Use and Land Cover Dynamics from 1976 to 2014 in Yellow River Delta. 6, 20.

Zhang, Q., Wang, J., Peng, X., Gong, P., Shi, P., 2002. Urban built-up land change detection with road density and spectral information from multi-temporal Landsat TM data. International Journal of Remote Sensing 23, 3057-3078. 